\title{
Hybrid complementary circuits based on p-channel organic and n-channel metal oxide transistors with balanced carrier mobilities of up to $10 \mathrm{~cm}^{2} / \mathrm{Vs}$
}

Ivan Isakov, Alexandra F. Paterson, Olga Solomeshch, Nir Tessler, Qiang Zhang, Jun Li, Xixiang Zhang, Zhuping Fei, Martin Heeney, and Thomas D. Anthopoulos

Citation: Appl. Phys. Lett. 109, 263301 (2016); doi: 10.1063/1.4972988

View online: http://dx.doi.org/10.1063/1.4972988

View Table of Contents: http://aip.scitation.org/toc/apl/109/26

Published by the American Institute of Physics

\section{Articles you may be interested in}

Amorphous ZnOxNy thin films with high electron Hall mobility exceeding $200 \mathrm{~cm} 2 \mathrm{~V}-1 \mathrm{~s}-1$

Appl. Phys. Lett. 109, 262101262101 (2016); 10.1063/1.4973203

High-performance PbS quantum dot vertical field-effect phototransistor using graphene as a transparent electrode

Appl. Phys. Lett. 109, 263101263101 (2016); 10.1063/1.4972984

$\mathrm{N}$-channel field-effect transistors with an organic-inorganic layered perovskite semiconductor

Appl. Phys. Lett. 109, 253301253301 (2016); 10.1063/1.4972404

High mobility BaSnO3 films and field effect transistors on non-perovskite $\mathrm{MgO}$ substrate

Appl. Phys. Lett. 109, 262102262102 (2016); 10.1063/1.4973205 


\title{
Hybrid complementary circuits based on $p$-channel organic and $n$-channel metal oxide transistors with balanced carrier mobilities of up to $10 \mathrm{~cm}^{2} / \mathrm{Vs}$
}

\author{
Ivan Isakov, ${ }^{1, a), b)}$ Alexandra F. Paterson, ${ }^{1, a)}$ Olga Solomeshch, ${ }^{2}$ Nir Tessler, ${ }^{2}$ Qiang Zhang, ${ }^{3}$ \\ Jun $\mathrm{Li}^{3}{ }^{3}$ Xixiang Zhang, ${ }^{3}$ Zhuping Fei, ${ }^{4}$ Martin Heeney, ${ }^{4}$ and Thomas D. Anthopoulos ${ }^{1, b)}$ \\ ${ }^{1}$ Department of Physics and Centre for Plastic Electronics, Blackett Laboratory, Imperial College London, \\ South Kensington, London SW7 2AZ, United Kingdom \\ ${ }^{2}$ Sara and Moshe Zisapel Nano-Electronic Center, Department of Electrical Engineering, Technion - Israel \\ Institute of Technology, Haifa 3200, Israel \\ ${ }^{3}$ King Abdullah University of Science and Technology (KAUST), Materials Science and Engineering, \\ Thuwal 23955-6900, Kingdom of Saudi Arabia \\ ${ }^{4}$ Department of Chemistry and Centre for Plastic Electronics, Imperial College London, South Kensington, \\ London SW7 2AZ, United Kingdom
}

(Received 26 October 2016; accepted 12 December 2016; published online 28 December 2016)

\begin{abstract}
We report the development of hybrid complementary inverters based on $p$-channel organic and $n$-channel metal oxide thin-film transistors (TFTs) both processed from solution at $<200{ }^{\circ} \mathrm{C}$. For the organic TFTs, a ternary blend consisting of the small-molecule 2,7-dioctyl[1]benzothieno[3,2b][1]benzothiophene, the polymer indacenodithiophene-benzothiadiazole $\left(\mathrm{C}_{16} \mathrm{IDT}-\mathrm{BT}\right)$ and the $p$-type dopant $\mathrm{C}_{60} \mathrm{~F}_{48}$ was employed, whereas the isotype $\mathrm{In}_{2} \mathrm{O}_{3} / \mathrm{ZnO}$ heterojunction was used for the $n$ channel TFTs. When integrated on the same substrate, $p$ - and $n$-channel devices exhibited balanced carrier mobilities up to $10 \mathrm{~cm}^{2} / \mathrm{Vs}$. Hybrid complementary inverters based on these devices show high signal gain $(>30 \mathrm{~V} / \mathrm{V})$ and wide noise margins $(70 \%)$. The moderate processing temperatures employed and the achieved level of device performance highlight the tremendous potential of the technology for application in the emerging sector of large-area microelectronics. Published by AIP Publishing. [http://dx.doi.org/10.1063/1.4972988]
\end{abstract}

Emerging technology concepts such as the Internet-ofThings (IoT), printed, flexible and wearable electronics and sensors depend on semiconductor technologies that are characterized by low cost, mechanical flexibility and high electrical performance. Although incumbent thin-film transistor (TFT) technologies such as those based on silicon (Si) satisfy most of the performance requirements, their manufacturing relies on complex, and hence costly, processes, whilst their mechanical properties are inadequate for flexible applications. ${ }^{1,2}$ As a result, in the last two decades, significant attention has been focused onto new material families such as organic and metal oxide semiconductors, ${ }^{3-6}$ both of which combine processing versatility with good electrical performance. ${ }^{7,8}$ Such attributes are anticipated to drastically reduce the manufacturing cost in comparison to, for example, vacuum-based manufacturing processes such as sputtering, atomic layer deposition (ALD), etc. In addition, the charge carrier mobilities of both organic and metal oxide TFTs have now surpassed the benchmark mobility of $10 \mathrm{~cm}^{2} / \mathrm{Vs}$, a value far superior to incumbent amorphous Si TFTs. ${ }^{9-12}$

Despite their unique attributes, organic and metal oxide semiconductors suffer from a common drawback, specifically their unipolar nature. For example, although a large number of high performance $p$-type organic semiconductors are readily available, their $n$-type counterparts are lacking in performance and stability. ${ }^{13}$ On the other hand, metal oxides are inherently $n$-type with only a few $p$-type metal oxides

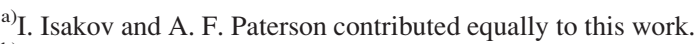

b) Authors to whom correspondence should be addressed. Electronic addresses: i.isakov@imperial.ac.uk and t.anthopoulos@imperial.ac.uk
}

known to date. ${ }^{4,12,14}$ This characteristic lack of suitable material systems hinders the development of the so-called complementary circuitry since the latter relies on the integration of $n$ - and the $p$-channel transistors on the same substrate. Complementary logic is of critical importance for the development of integrated circuits, as it enables both a dramatic reduction of the circuit's power dissipation, as compared to the unipolar logic circuits, and large-scale integration with high manufacturing yield. ${ }^{15-18}$ To address this issue, significant efforts have been made to develop hybrid complementary circuits by combining $p$-channel organic TFTs with $n$-channel metal oxide TFTs. ${ }^{19-22}$ However, the vast majority of the hybrid circuits demonstrated to date rely on costly vacuumbased processing techniques such as sputtering, ${ }^{19,20,23} \mathrm{ALD},{ }^{24}$ and/or required high temperature processing that is incompatible with inexpensive flexible substrate materials such as plastic. $^{25,26}$ Although significant progress towards plasticcompatible, solution-processed hybrid logic has been achieved in the recent years, these circuits show moderate performance primarily due to the large imbalance in the hole and electron mobilities. $^{27-30}$

Here, we report the development of complementary logic inverters (NOT gates) based on combination of organic and metal oxide TFTs processed from solution-phase at temperatures in the range $100-200^{\circ} \mathrm{C}$. Both the types of devices exhibit balanced hole and electron transport with mobility values in the range of $5-10 \mathrm{~cm}^{2} / \mathrm{Vs}$. These high mobilities are achieved through the use of a third generation $p$-type organic blend semiconductor ${ }^{11}$ and an $n$-type isotype $\operatorname{In}_{2} \mathrm{O}_{3} /$ $\mathrm{ZnO}$ heterojunction, ${ }^{7}$ for the $p$-channel and $n$-channel TFTs, respectively. By combining the $p$ - and $n$-channel TFTs, we 
demonstrate the functional complementary circuits with state-of-the-art performance characteristics.

The metal oxide precursor solutions were prepared by dissolving indium nitrate hydroxide (Indium Corporation) in 2methoxyethanol (Sigma) at a concentration of $20 \mathrm{mg} / \mathrm{ml}$ and zinc oxide nanoparticles (Sigma Aldrich) in ammonium hydroxide solution (50 w\%, Sigma) at a concentration of $10 \mathrm{mg} / \mathrm{ml}$. Organic blend solutions were prepared at a concentration of $10 \mathrm{mg} / \mathrm{ml}$ using the small molecule 2,7-dioctyl[1]benzothieno[3,2-b][1]benzothiophene $\left(\mathrm{C}_{8}\right.$-BTBT) blended with polymer indacenodithiophene-benzothiadiazole $\left(\mathrm{C}_{16} \mathrm{IDT}\right.$ $\mathrm{BT})$ at a ratio of 1:4 using a solvent mixture of tetralin and chlorobenzene (1:1). The molecular dopant $\mathrm{C}_{60} \mathrm{~F}_{48}$ was then added at $1 \%$ molar weight following the previously described procedures. ${ }^{11}$ Figure 1(a) shows the chemical structures of the various materials used. The wafers of degenerately $n$-doped $\mathrm{Si}$ with $400 \mathrm{~nm}$-thick $\mathrm{SiO}_{2}$ acting as the gate and dielectric, respectively, were employed for the fabrication of discrete bottom-gate, top-contact (BG-TC) metal oxide TFTs (Figure 1(b)), while organic TFTs were fabricated on glass substrates using a top-gate, bottom-contact (TG-BC) architecture (Figure 1(c)) using the previously described procedures. ${ }^{11}$ All the substrates were cleaned prior to materials deposition by ultrasonication in baths of deionised water, acetone and 2propanol for 10 minutes each and were subjected to UVozone for $15 \mathrm{~min}$. The $\mathrm{In}_{2} \mathrm{O}_{3}$ precursor formulation was spincoated onto $\mathrm{Si}^{++} / \mathrm{SiO}_{2}$ wafers at $4000 \mathrm{rpm}$ for $30 \mathrm{~s}$ followed by thermal annealing at $200^{\circ} \mathrm{C}$ in air for $1 \mathrm{~h}$. The $\mathrm{In}_{2} \mathrm{O}_{3} / \mathrm{ZnO}$ heterojunction was completed with the spin coating of the top ZnO layer. ${ }^{7}$ The TFTs were completed with the deposition of
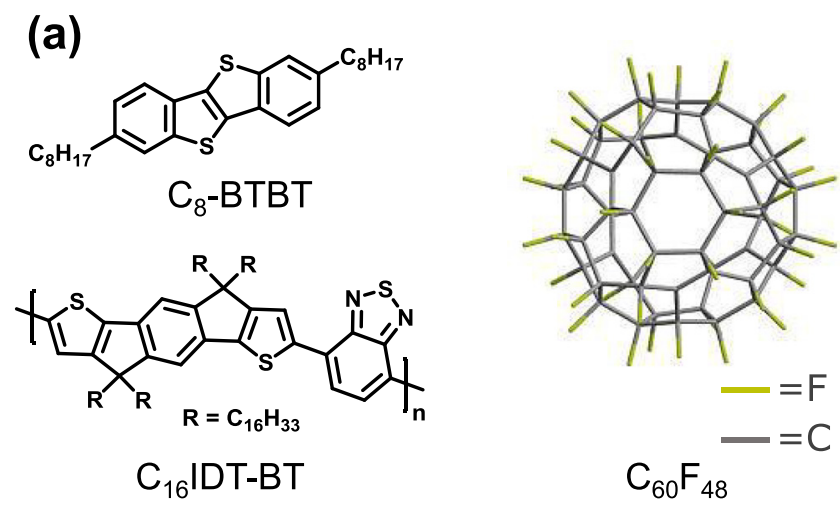

(b)

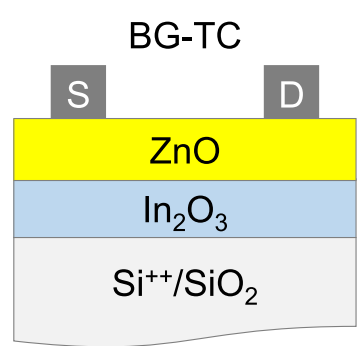

(c)

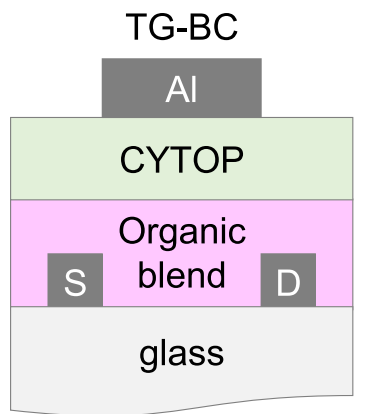

FIG. 1. (a) Chemical structure of 2,7-dioctyl[1]benzothieno[3,2-b][1]benzothiophene $\left(\mathrm{C}_{8}\right.$-BTBT), indacenodithiophene-benzothiadiazole $\left(\mathrm{C}_{16} \mathrm{IDT}-\mathrm{BT}\right)$ and the molecular $p$-dopant $\mathrm{C}_{60} \mathrm{~F}_{48}$. Schematics of the transistor architectures employed: (b) metal oxide bottom-gate, top-contact (BG-TC) TFT, and (c) organic blend top-gate, bottom-contact (TG-BC) TFT.
$40 \mathrm{~nm}$-thick top Al source-drain (S-D) electrodes via thermal vacuum sublimation. For the inverter fabrication, first, the $\mathrm{In}_{2} \mathrm{O}_{3} / \mathrm{ZnO}$ was deposited and patterned via conventional photolithography using the Microposit S1813 photoresist (Shipley) and the MF-26A developer. Developed areas were removed in $37 \%$ hydrochloric acid, while resist residuals were removed by acetone. The S-D electrodes were deposited via thermal evaporation of a $10 \mathrm{~nm}$-thick layer of $\mathrm{Al}$, acting as the adhesion and electron injecting layer for the metal oxide channel, and a $30 \mathrm{~nm}$-thick hole injecting Au layer, followed by the deposition of the electrode work function modifying self-assembling molecule 2,3,4,5,6-Pentafluorothiophenol (PFBT). ${ }^{22}$ Circuit fabrication was completed with the deposition of the ternary $\mathrm{C}_{8}$-BTBT: $\mathrm{C}_{16}$ IDT-BT: $\mathrm{C}_{60} \mathrm{~F}_{48}(1 \%)$ blend, $900 \mathrm{~nm}$ thick CYTOP gate dielectric and the top Al gate electrode. The film microstructures were studied by high-resolution transmission electron microscopy (HRTEM). The electrical characterization of the TFTs and inverter circuits were performed in nitrogen at room temperature using an Agilent B2902A and Keithley 4200 semiconductor parameter analysers, respectively.

The $n$-type metal oxides $\mathrm{In}_{2} \mathrm{O}_{3}, \mathrm{ZnO}, \mathrm{Ga}_{2} \mathrm{O}_{3}$ and their alloys are the most widely studied semiconductors for TFT applications. $^{31,32}$ Although it has been proven difficult to achieve high electron mobilities using these materials when processed at temperatures $<200{ }^{\circ} \mathrm{C}$, various methods have been developed to overcome this limitation, including combustion synthesis, photonic annealing and chemical doping. ${ }^{8,33-36}$ In this work, we exploited the recently proposed $\mathrm{In}_{2} \mathrm{O}_{3} / \mathrm{ZnO}$ heterojunction channel architecture to improve the TFT's electron mobility, while maintaining the processing temperature below $200^{\circ} \mathrm{C}$. $^{7}$ The main advantage of using such bilayer channels is demonstrated in Figure 2(a), where the transfer characteristics of TFTs based on single layers of $\mathrm{ZnO}$ and $\mathrm{In}_{2} \mathrm{O}_{3}$, compared with the transfer characteristics of an $\mathrm{In}_{2} \mathrm{O}_{3} / \mathrm{ZnO}$ bilayer, are plotted on the same graph. $\mathrm{In}_{2} \mathrm{O}_{3} /$ ZnO TFTs exhibit consistently higher channel current $\left(I_{\mathrm{D}}\right)$ than $\mathrm{In}_{2} \mathrm{O}_{3}$ and $\mathrm{ZnO}$ TFTs, indicative of higher electron mobility $(\mu)$. In particular, the average $\mu$ calculated over ten $\mathrm{ZnO}$ TFTs and ten $\mathrm{In}_{2} \mathrm{O}_{3}$ TFTs were $\sim 1 \mathrm{~cm}^{2} / \mathrm{Vs}$ and $2 \mathrm{~cm}^{2} /$ Vs, respectively, whereas $\mathrm{In}_{2} \mathrm{O}_{3} / \mathrm{ZnO}$ TFTs yielded electron mobilities in the range of $5-11 \mathrm{~cm}^{2} / \mathrm{Vs}$, in accordance with the previous work. ${ }^{7}$ The improved performance of the $\operatorname{In}_{2} \mathrm{O}_{3} /$ $\mathrm{ZnO}$ transistors is attributed to its high quality heterointerface, which results in the formation of a sheet of free electrons confined at its vicinity. ${ }^{7}$ The latter enables access to the extended states in the conduction band of $\mathrm{In}_{2} \mathrm{O}_{3}$ leading to band-like charge transport characteristics. Direct evidence for the presence of a high quality heterointerface is provided by the cross-sectional HRTEM analysis [inset in Figure 2(a)], which reveals discrete polycrystalline $\mathrm{In}_{2} \mathrm{O}_{3}$ and $\mathrm{ZnO}$ layers separated by a chemically sharp interface.

The next step for the complementary circuit fabrication was to realise $p$-channel TFTs with a comparable level of performance to $\mathrm{In}_{2} \mathrm{O}_{3} / \mathrm{ZnO}$ TFTs. We have chosen organic semiconducting small molecule/polymer blends, as in recent years they have been shown to outperform the majority of organic semiconductors in TFTs. ${ }^{11,37,38}$ The excellent performance of such blend systems is attributed to the vertical phase separation of the two materials during solvent 


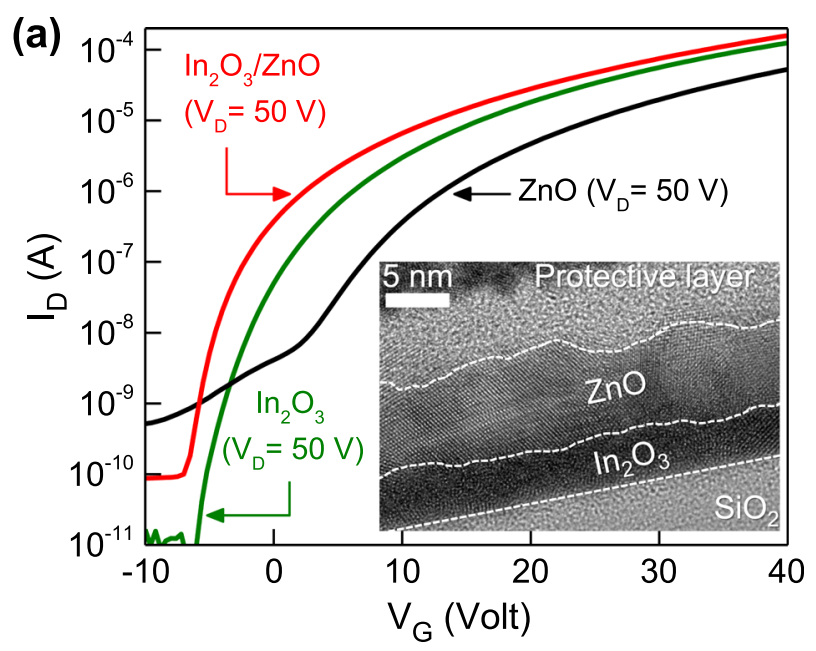

(b)

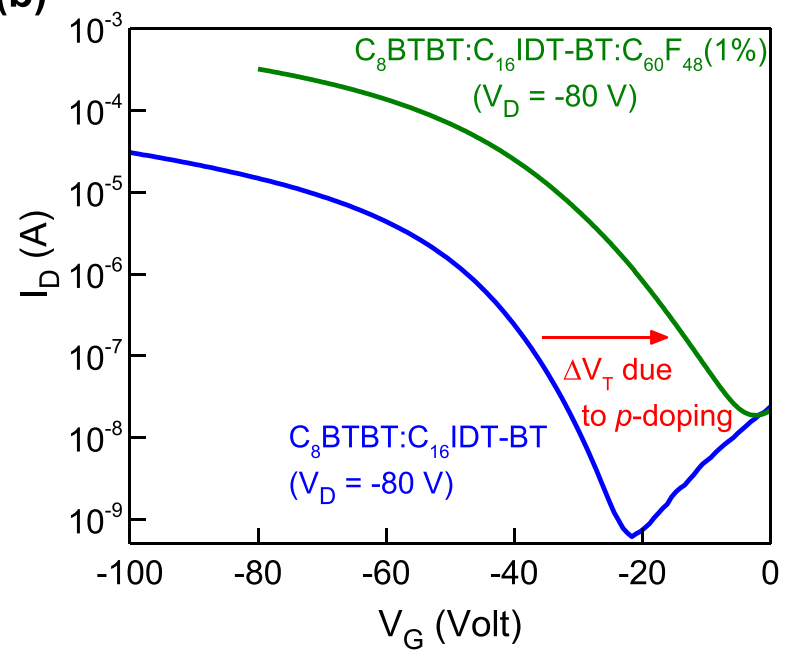

FIG. 2. (a) Transfer characteristics of single layer $\operatorname{In}_{2} \mathrm{O}_{3}, \mathrm{ZnO}$ and bilayer $\mathrm{In}_{2} \mathrm{O}_{3} / \mathrm{ZnO}$ TFTs with $\mathrm{L}=50 \mu \mathrm{m}, \mathrm{W}=1000 \mu \mathrm{m}$. Inset: cross-sectional HRTEM image of the isotype $\operatorname{In}_{2} \mathrm{O}_{3} / \mathrm{ZnO}$ heterointerface. (b) Transfer characteristics of undoped $\mathrm{C}_{8}-\mathrm{BTBT}: \mathrm{C}_{16} \mathrm{IDT}-\mathrm{BT}$ and $p$-doped $\mathrm{C}_{8}$-BTBT: $\mathrm{C}_{16}$ IDT-BT: $\mathrm{C}_{60} \mathrm{~F}_{48}(1 \%)$ TFTs with $\mathrm{L}=80 \mu \mathrm{m}, \mathrm{W}=1000 \mu \mathrm{m}$.

evaporation, where the small molecule diffuses to the surface of the film, leading to the formation of a highly crystalline channel layer. This unique microstructure has been shown to facilitate low conductivity grain boundaries and as a result exhibits excellent hole transport characteristics. ${ }^{39}$ For the purpose of this study, we employed a ternary blend of $\mathrm{C}_{8^{-}}$ BTBT: $\mathrm{C}_{16}$ IDT-BT $p$-doped with $\mathrm{C}_{60} \mathrm{~F}_{48}\left(\mathrm{C}_{8}\right.$-BTBT: $\mathrm{C}_{16}$ IDT$\left.\mathrm{BT}: \mathrm{C}_{60} \mathrm{~F}_{48}(1 \%)\right)$, which has shown to exhibit significantly improved hole transport characteristics with maximum hole mobility values exceeding $13 \mathrm{~cm}^{2} / \mathrm{Vs}{ }^{11}$ Figure 2 (b) shows the transfer characteristics of $\mathrm{C}_{8}$-BTBT: $\mathrm{C}_{16}$ IDT-BT TFTs before and after $p$-doping with $\mathrm{C}_{60} \mathrm{~F}_{48}(1 \%)$, with the $p$-doping having a dramatic impact on the TFT operation. The addition of $\mathrm{C}_{60} \mathrm{~F}_{48}$ is found to suppress electron transport, reduce $\mathrm{V}_{\mathrm{TH}}$ from $-36 \mathrm{~V}$ to $-25 \mathrm{~V}$ (Figure 2(b) and Figure S1 of supplementary material), minimize operating hysteresis and increase the ON current and the OFF current, which are all indicative signs of $p$-type doping. The most significant outcome of the $p$ doping in this system is the dramatic increase in the hole mobility. By calculating average mobility values from 16 TFTs, the hole mobility was found to increase from $2.4 \mathrm{~cm}^{2} /$ $\mathrm{Vs}$ in the pristine $\mathrm{C}_{8}$-BTBT: $\mathrm{C}_{16}$ IDT-BT blend OTFTs to
$9.4 \mathrm{~cm}^{2} / \mathrm{Vs}$ for the doped $\mathrm{C}_{8}$-BTBT: $\mathrm{C}_{16}$ IDT-BT: $\mathrm{C}_{60} \mathrm{~F}_{48}(1 \%)$ devices, demonstrating the robust performance of these ternary blend OTFTs. The improvements in mobility and operational characteristics can be attributed to the dopant that deactivates deep traps and generates additional mobile holes within the system. ${ }^{11}$ In addition, the vertical phase segregation of the polymer and small molecule can be experimentally verified by comparing the operating characteristics of OTFTs based on the bottom and top gate architecture (Figure S2 of supplementary material). Upon layer deposition, $\mathrm{C}_{8}$-BTBT segregates to the top of the composite layer forming a high mobility channel. As a result, top-gate devices perform extremely well. This is not the case for the bottom-gate OTFT where charge transport is found to be extremely poor with the channel currents typically 3-4 orders of magnitude lower than in top gate OTFTs.

The balanced performance makes the combination of $n$ channel $\mathrm{In}_{2} \mathrm{O}_{3} / \mathrm{ZnO}$ TFTs with $p$-channel $\mathrm{C}_{8}$-BTBT: $\mathrm{C}_{16}$ IDT$\mathrm{BT}: \mathrm{C}_{60} \mathrm{~F}_{48}$ TFTs an attractive option for realizing complementary logic circuits. To demonstrate the potential of the proposed technology, integrated NOT gates were designed and fabricated. Figures 3(a) and 3(b) show the circuitry and a schematic of its physical layout. The inverter consists of a BG-TC $n$-channel $\mathrm{In}_{2} \mathrm{O}_{3} / \mathrm{ZnO}$ TFT with a common gate and a TG-BC $p$-channel $\mathrm{C}_{8}$-BTBT: $\mathrm{C}_{16}$ IDT-BT: $\mathrm{C}_{60} \mathrm{~F}_{48}$ TFT. The Al layer deposited on the organic blend layer above the $n$ channel TFTs only serves as an encapsulation layer and remains floating during TFT/circuit operation. The width and
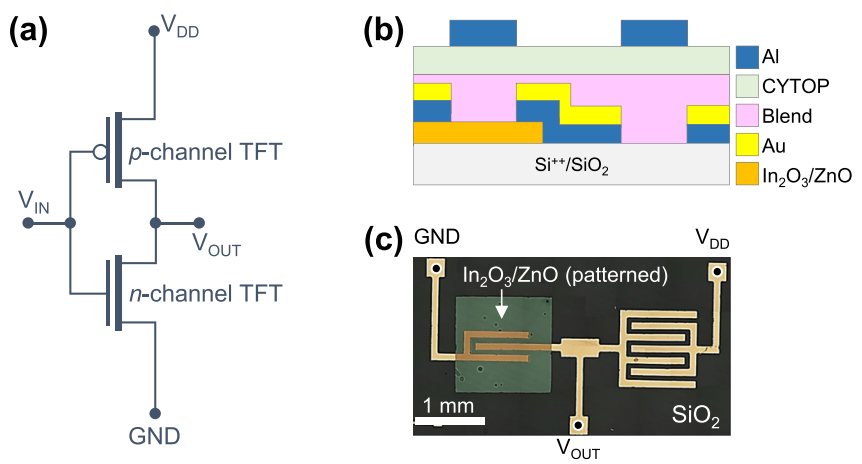

(d)

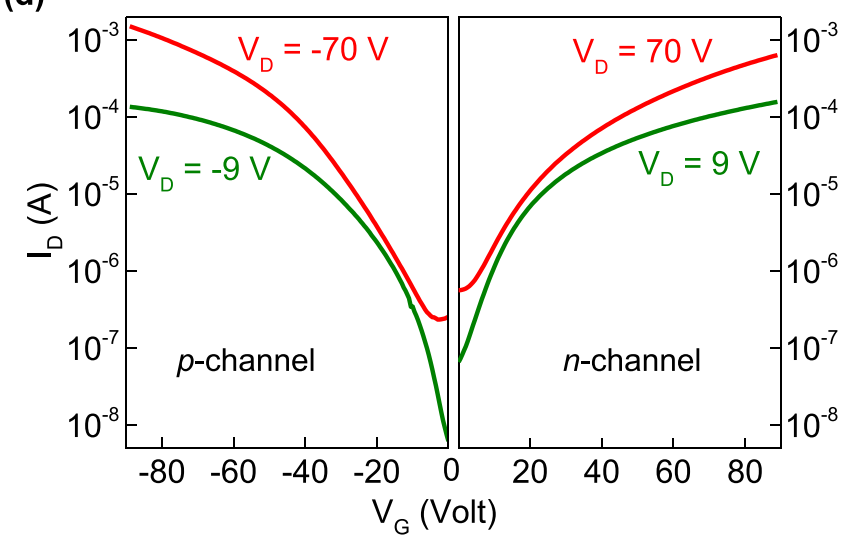

FIG. 3. (a) Circuit diagram of the complementary inverter. (b) Crosssectional schematics of the hybrid complementary inverter. (c) Intermediate step of the inverter fabrication: optical micrograph of the structure after metal oxide patterning and S-D deposition prior to the deposition of organic semiconductor. (d) Transfer characteristics of the organic blend transistor and metal oxide transistor after complete inverter fabrication. 
length (W/L) of the $p$ - and $n$-channel transistors used were $7000 \mu \mathrm{m} / 100 \mu \mathrm{m}$ and $1000 \mu \mathrm{m} / 100 \mu \mathrm{m}$, respectively. To minimize parasitic effects, the $\mathrm{In}_{2} \mathrm{O}_{3} / \mathrm{ZnO}$ heterojunction was deposited first and patterned laterally (Figure 3(c)) using standard photolithography, followed by the deposition of the organic blend and CYTOP layers on the entire substrate. Importantly, the $p$-channel transistor operation is governed solely by the top $\mathrm{Al}$ gate since the influence of the bottom $\mathrm{Si}^{++}$gate field on the organic channel is marginal (Figure S2 of supplementary material). Finally, the $n$-channel transistor is equipped with a floating Al top-gate (Figure 3(b)). The latter metal layer does not affect electron transport occurring at the $\mathrm{SiO}_{2} / \mathrm{In}_{2} \mathrm{O}_{3} / \mathrm{ZnO} / \mathrm{C}_{8}$-BTBT: $\mathrm{C}_{16}$ IDT-BT: $\mathrm{C}_{60} \mathrm{~F}_{48}$ interface and only serves as an encapsulation layer.

Figure 3(d) shows the transfer characteristics of an $n$-channel $\operatorname{In}_{2} \mathrm{O}_{3} / \mathrm{ZnO}$ TFT and a $p$-channel organic blend TFT measured independently following inverter fabrication. The geometric capacitance of the CYTOP and the $\mathrm{SiO}_{2}$ dielectrics, as well as the channel geometries, were chosen so that both TFTs exhibit similar operating characteristics with comparable performance. It should be noted that patterning of the $\operatorname{In}_{2} \mathrm{O}_{3} / \mathrm{ZnO}$ layer affects the device characteristics and shifts the $\mathrm{V}_{\mathrm{TH}}$ to more positive values by approximately $15 \mathrm{~V}$ without affecting the ON-current or the charge mobility values (Figure S3 of supplementary material). As a result, the patterned $p$ - and $n$-type TFTs (Figure 3(d)) exhibit similar $\mathrm{V}_{\mathrm{TH}}$ and turn-on voltages. The only negative side effect of the organic blend layer being deposited onto the $n$-channel (Figure 3(b)) is the increase in the channel OFF currents from $10^{-11}$ to $10^{-7}$ A (Figure 3(d)). This parasitic contribution to channel current, however, is minimal and does not affect the charge mobility calculations. Analysis of the transfer characteristics in Figure 3(d) yields electron and hole mobility values (at $V_{\mathrm{G}}= \pm 80 \mathrm{~V}$ ) that are very similar and typically in the range of $5-10 \mathrm{~cm}^{2} /$ Vs. These values are the highest reported to date for any solution-processed $p$-channel organic TFTs and $n$-channel metal oxide TFTs integrated onto the same substrate and demonstrate the potential of the proposed technology.

Figure 4 shows the quasistatic voltage transfer characteristics (VTC) of the hybrid complementary inverter and the

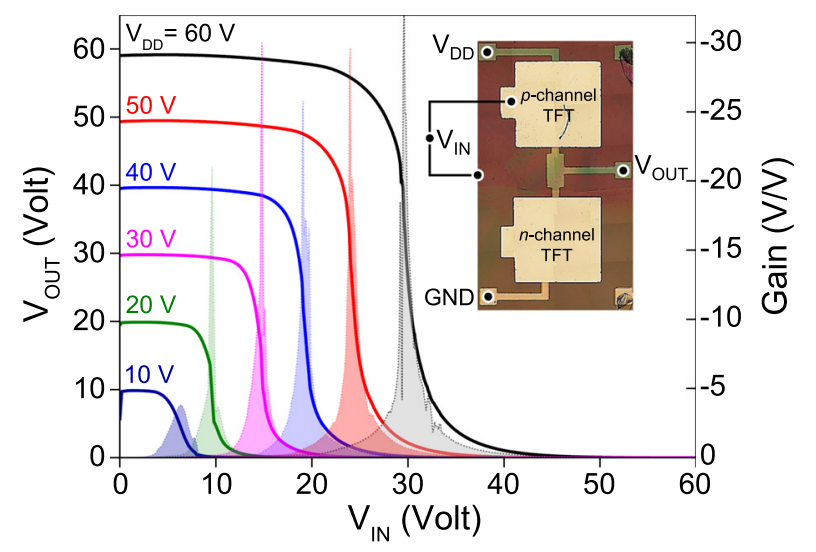

FIG. 4. Complementary inverter transfer characteristics and inverter differential gain (shaded areas). Inset: optical micrograph of a completed inverter structure showing the $p$-channel top gate and the $n$-channel bottom gate, and a floating $n$-channel top gate. corresponding signal gain $(\mathrm{V} / \mathrm{V})$ curves measured at different supply voltages $\left(V_{\mathrm{DD}}\right)$, whilst the inset shows a microscope image of the actual integrated circuit. The inverter exhibits excellent operation with nearly ideal rail-to-rail output voltage $\left(V_{\text {OUT }}\right)$ swing and a sharp transition at input voltages $\left(V_{\mathrm{IN}}\right)$ equal to $V_{\mathrm{DD}} / 2$, especially at $V_{\mathrm{DD}} \geq 20 \mathrm{~V}$. This feature leads to high differential voltage gain $\left(\mathrm{G}=d V_{\mathrm{OUT}} / d V_{\mathrm{IN}}\right)$ of $>30 \mathrm{~V} / \mathrm{V}$, for $V_{\mathrm{DD}} \geq 30 \mathrm{~V}$ (shaded areas in Figure 4); a $\mathrm{G}$ magnitude of $>1$ is required for sustained signal propagation in an integrated circuit comprising a large number of logic gates/stages. Finally, the circuit exhibits large noise margins of $\sim 70 \%$ for $\mathrm{V}_{\mathrm{DD}} \geq 20 \mathrm{~V}$, which makes it highly immune to input signal noise, further demonstrating the potential of the proposed hybrid circuits within the emerging area of printed microelectronics. ${ }^{15}$

In summary, we have demonstrated hybrid complementary integrated circuits based on a combination of high performance isotype $\operatorname{In}_{2} \mathrm{O}_{3} / \mathrm{ZnO}$ heterojunctions and organic blend $\mathrm{C}_{8}$-BTBT: $\mathrm{C}_{16} \mathrm{IDT}-\mathrm{BT}: \mathrm{C}_{60} \mathrm{~F}_{48}(1 \%)$ as the $n$ - and $p$-channel TFTs, respectively. We showed that both devices can be integrated on the same substrate using solution-based processing techniques at plastic-compatible temperatures of $<200^{\circ} \mathrm{C}$. The resulting TFTs exhibit balanced carrier mobilities in the range of $5-10 \mathrm{~cm}^{2} / \mathrm{Vs}$. Hybrid complementary inverters based on these TFTs show excellent rail-to-rail output voltage swing with voltage signal gain of $>30 \mathrm{~V} / \mathrm{V}$ and noise margins in excess of $70 \%$. The manufacturability and level of performance makes the proposed hybrid circuit architecture a realistic possibility for cost effective and scalable manufacturing of large area microelectronics.

See supplementary material for further experimental results.

T.D.A., I.I., and A.F.P acknowledge the financial support from Cambridge Display Technology Limited (Company No. 2672530). Q.Z., J.L., and X.X.Z. are supported financially by KAUST. O.S. acknowledges the support of the Center for Absorption in Science of the Ministry of Immigrant Absorption under the framework of the KAMEA Program.

${ }^{1}$ D. Kim and J. A. Rogers, "Stretchable electronics: Materials strategies and devices," Adv. Mater. 20(24), 4887-4892 (2008).

${ }^{2}$ Y. Sun and J. A. Rogers, "Inorganic semiconductors for flexible electronics," Adv. Mater. 19(15), 1897-1916 (2007).

${ }^{3}$ K. Nomura, H. Ohta, A. Takagi, T. Kamiya, M. Hirano, and H. Hosono, "Room-temperature fabrication of transparent flexible thin-film transistors using amorphous oxide semiconductors," Nature 432(7016), 488-492 (2004).

${ }^{4}$ L. Petti, N. Münzenrieder, C. Vogt, H. Faber, L. Büthe, G. Cantarella, T. D. Anthopoulos, and G. Tröster, "Metal oxide semiconductor thin-film transistors for flexible electronics Metal oxide semiconductor thin-film transistors for flexible electronics," AIP Appl. Phys. Rev. 3, 021303 (2016).

${ }^{5}$ H. Dong, X. Fu, J. Liu, Z. Wang, and W. Hu, "25th anniversary article: Key points for high-mobility organic field-effect transistors," Adv. Mater. 25(43), 6158-6183 (2013).

${ }^{6} \mathrm{H}$. Sirringhaus, "25th anniversary article: Organic field-effect transistors: The path beyond amorphous silicon," Adv. Mater. 26(9), 1319-1335 (2014).

${ }^{7}$ Y.-H. Lin, H. Faber, J. G. Labram, E. Stratakis, L. Sygellou, E. Kymakis, N. A. Hastas, R. Li, K. Zhao, A. Amassian, N. D. Treat, M. McLachlan, and T. D. Anthopoulos, "High electron mobility thin-film transistors based 
on solution-processed semiconducting metal oxide heterojunctions and quasi-superlattices,” Adv. Sci. 2, 1500058 (2015).

${ }^{8}$ H. Faber, Y.-H. Lin, S. R. Thomas, K. Zhao, N. Pliatsikas, M. A. McLachlan, A. Amassian, P. A. Patsalas, and T. D. Anthopoulos, "Indium oxide thin-film transistors processed at low temperature via ultrasonic spray pyrolysis," ACS Appl. Mater. Interfaces 7(1), 782-790 (2015).

${ }^{9}$ S. Y. Han, G. S. Herman, and C. H. Chang, "Low-temperature, highperformance, solution-processed indium oxide thin-film transistors," J. Am. Chem. Soc. 133(14), 5166-5169 (2011).

${ }^{10} \mathrm{H}$. Hosono, "Ionic amorphous oxide semiconductors: Material design, carrier transport, and device application," J. Non-Cryst. Solids. 352, 851-858 (2006).

${ }^{11}$ A. F. Paterson, N. D. Treat, W. Zhang, Z. Fei, G. Wyatt-Moon, H. Faber, G. Vourlias, P. A. Patsalas, O. Solomeshch, N. Tessler, M. Heeney, and T. D. Anthopoulos, "Small molecule/polymer blend organic transistors with hole mobility exceeding $13 \mathrm{~cm}^{2} \mathrm{~V}^{-1} \mathrm{~s}^{-1}$," Adv. Mater. 28, 7791-7798 (2016).

${ }^{12}$ J. G. Labram, Y. H. Lin, and T. D. Anthopoulos, "Exploring twodimensional transport phenomena in metal oxide heterointerfaces for nextgeneration, high-performance, thin-film transistor technologies," Small 11(41), 5472-5482 (2015).

${ }^{13}$ J. E. Anthony, A. Facchetti, M. Heeney, S. R. Marder, and X. Zhan, "Ntype organic semiconductors in organic electronics," Adv. Mater. 22(34), 3876-3892 (2010).

${ }^{14}$ P. Pattanasattayavong, S. Thomas, G. Adamopoulos, M. A. McLachlan, and T. D. Anthopoulos, "P-channel thin-film transistors based on spraycoated Cu2O films," Appl. Phys. Lett. 102, 163505 (2013).

${ }^{15}$ G. Gelinck, P. Heremans, K. Nomoto, and T. D. Anthopoulos, "Organic transistors in optical displays and microelectronic applications," Adv. Mater. 22(34), 3778-3798 (2010).

${ }^{16}$ K. J. Baeg, D. Khim, J. Kim, D. Y. Kim, S. W. Sung, B. Do Yang, and Y. Y. Noh, "Flexible complementary logic gates using inkjet-printed polymer field-effect transistors," IEEE Electron Device Lett. 34(1), 126-128 (2013).

${ }^{17}$ K. J. Baeg, S. W. Jung, D. Khim, J. Kim, D. Y. Kim, J. B. Koo, J. R. Quinn, A. Facchetti, I. K. You, and Y. Y. Noh, "Low-voltage, high speed inkjet-printed flexible complementary polymer electronic circuits," Organic Electronics 14(5), 1407-1418 (2013).

${ }^{18}$ K. J. Baeg, M. Caironi, and Y. Y. Noh, "Toward printed integrated circuits based on unipolar or ambipolar polymer semiconductors," Adv. Mater. 25(31), 4210-4244 (2013).

${ }^{19}$ M. S. Oh, D. K. Hwang, K. Lee, W. J. Choi, J. H. Kim, S. Im, S. Lee, M. S. Oh, D. K. Hwang, K. Lee, W. J. Choi, J. H. Kim, S. Im, and S. Lee, "Pentacene and $\mathrm{ZnO}$ hybrid channels for complementary thin-film transistor inverters operating at 2 V," J. Appl. Phys. 102, 076104 (2007).

${ }^{20}$ J. H. Na, M. Kitamura, Y. Arakawa, J. H. Na, M. Kitamura, and Y. Arakawa, "Organic/inorganic hybrid complementary circuits based on pentacene and amorphous indium gallium zinc oxide transistors," Appl. Phys. Lett. 93, 213505 (2008).

${ }^{21}$ J. B. Kim, C. Fuentes-Hernandez, S. J. Kim, S. Choi, and B. Kippelen, "Flexible hybrid complementary inverters with high gain and balanced noise margins using pentacene and amorphous InGaZnO thin-film transistors," Organic Electronics 11(6), 1074-1078 (2010).

${ }^{22}$ J. Smith, A. Bashir, G. Adamopoulos, J. E. Anthony, D. D. C. Bradley, R. Hamilton, M. Heeney, I. McCulloch, and T. D. Anthopoulos, "Air-stable solution-processed hybrid transistors with hole and electron mobilities exceeding 2 cm2v-1 s-1," Adv. Mater. 22(32), 3598-3602 (2010).

${ }^{23}$ J. B. Kim, C. Fuentes-Hernandez, D. K. Hwang, W. J. Potscavage, H. Cheun, and B. Kippelen, "Vertically stacked hybrid organic-inorganic complementary inverters with low operating voltage on flexible substrates," Organic Electronics 12(1), 45-50 (2011).
${ }^{24}$ Y. V. Li, D. A. Mourey, M. A. Loth, D. A. Zhao, J. E. Anthony, and T. N. Jackson, "Hybrid inorganic/organic complementary circuits using PEALD $\mathrm{ZnO}$ and ink-jet printed diF-TESADT TFTs," Organic Electronics 14(10), 2411-2417 (2013).

${ }^{25}$ W. Zhang, J. Smith, S. E. Watkins, R. Gysel, M. McGehee, A. Salleo, J. Kirkpatrick, S. Ashraf, T. Anthopoulos, M. Heeney, and I. McCulloch, "Indacenodithiophene semiconducting polymers for high-performance, air-stable transistors," J. Am. Chem. Soc. 132(33), 11437-11439 (2010).

${ }^{26}$ Y. S. Rim, H. Chen, Y. Liu, S. H. Bae, H. J. Kim, and Y. Yang, "Direct light pattern integration of low-temperature solution-processed all-oxide flexible electronics," ACS Nano 8(9), 9680-9686 (2014).

${ }^{27}$ V. Pecunia, K. Banger, A. Sou, and H. Sirringhaus, "Solution-based selfaligned hybrid organic/metal-oxide complementary logic with megahertz operation," Organic Electronics 21, 177-183 (2015).

${ }^{28}$ X. Guo, L. Feng, Q. Cui, and X. Xu, "Low voltage organic/inorganic hybrid complementary inverter with low temperature all solution processed semiconductor and dielectric layers," IEEE Electron Device Lett. 35(5), 542-544 (2014).

${ }^{29}$ M. Rockele, D. V. Pham, A. Hoppe, J. Steiger, S. Botnaras, M. Nag, S. Steudel, K. Myny, S. Schols, R. Müller, B. Van Der Putten, J. Genoe, and P. Heremans, "Low-temperature and scalable complementary thin-film technology based on solution-processed metal oxide n-TFTs and pentacene p-TFTs," Organic Electronics 12(11), 1909-1913 (2011).

${ }^{30}$ K. Myny, S. Smout, M. Rockelé, A. Bhoolokam, T. H. Ke, S. Steudel, B. Cobb, A. Gulati, F. Gonzalez Rodriguez, K. Obata, M. Marinkovic, D.-V. Pham, A. Hoppe, G. H. Gelinck, J. Genoe, W. Dehaene, and P. Heremans, "A thin-film microprocessor with inkjet print-programmable memory," Sci. Rep. 4, 7398 (2014).

${ }^{31}$ E. Fortunato, P. Barquinha, and R. Martins, "Oxide semiconductor thinfilm transistors: A review of recent advances," Adv. Mater. 24(22), 2945-2986 (2012).

${ }^{32} \ddot{U}$. Özgür, D. Hofstetter, and H. Morkoc, "ZnO Devices and Applications: A Review of Current Status and Future Prospects," Proc. IEEE 98(7), 1255-1268 (2010).

${ }^{33}$ Y. H. Lin, H. Faber, K. Zhao, Q. Wang, A. Amassian, M. McLachlan, and T. D. Anthopoulos, "High-performance $\mathrm{ZnO}$ transistors processed via an aqueous carbon-free metal oxide precursor route at temperatures between 80-180 C," Adv. Mater. 25(31), 4340-4346 (2013).

${ }^{34}$ Y. Lin, S. R. Thomas, H. Faber, R. Li, M. A. Mclachlan, P. A. Patsalas, and T. D. Anthopoulos, "Al-Doped ZnO Transistors Processed from Solution at $120^{\circ}$ C," Adv. Electron. Mater. 2, 1600070 (2016).

${ }^{35}$ M.-G. Kim, M. G. Kanatzidis, A. Facchetti, and T. J. Marks, "Low-temperature fabrication of high-performance metal oxide thin-film electronics via combustion processing," Nat. Mater. 10(5), 382-388 (2011).

${ }^{36}$ Y. Hwan Hwang, J.-S. Seo, J. Moon Yun, H. Park, S. Yang, S.-H. Ko Park, and B.-S. Bae, "An 'aqueous route' for the fabrication of low-temperature-processable oxide flexible transparent thin-film transistors on plastic substrates," NPG Asia Mater. 5, e45 (2013).

${ }^{37}$ R. Hamilton, J. Smith, S. Ogier, M. Heeney, J. E. Anthony, I. McCulloch, J. Veres, D. D. C. Bradley, and T. D. Anthopoulos, "High-performance polymer-small molecule blend organic transistors," Adv. Mater. 21, 1166-1171 (2009).

${ }^{38}$ J. Smith, W. Zhang, R. Sougrat, K. Zhao, R. Li, D. Cha, A. Amassian, M. Heeney, I. McCulloch, and T. D. Anthopoulos, "Solution-processed small molecule-polymer blend organic thin-film transistors with hole mobility greater than 5 cm2/Vs," Adv. Mater. 24(18), 2441-2446 (2012).

${ }^{39}$ S. Hunter and T. D. Anthopoulos, "Observation of unusual, highly conductive grain boundaries in high-mobility phase separated organic semiconducting blend films probed by lateral-transport," Adv. Mater. 25, $4320-4326$ (2013). 